\title{
Laser phototherapy induces angiogenesis in the periodontal tissue after delayed tooth replantation in rats
}

\author{
Felipe-de Souza Matos 1, Fernanda-de Jesus Godolphim 2, Ricardo-Luiz-Cavalcanti Albuquerque-Júnior ${ }^{3}$, \\ Luiz-Renato Paranhos ${ }^{4}$, Sigmar-de Mello Rode ${ }^{5}$, Cláudio-Antonio-Talge Carvalho ${ }^{6}$, Maria-Amália-Gonzaga \\ Ribeiro $^{4}$
}

${ }^{1}$ DDS, MSc, Department of Restorative Dentistry, Endodontic Division, Institute of Science and Technology, São Paulo State University, São José dos Campos, SP, Brazil

${ }^{2}$ DDS, Department of Dentistry, Federal University of Sergipe, Aracaju, SE, Brazil

${ }^{3}$ DDS, MSc, PhD, Professor, Department of Dentistry, Tiradentes University, Aracaju, SE, Brazil

${ }^{4}$ DDS, MSc, PhD, Professor, Department of Dentistry, Federal University of Sergipe, Aracaju, SE, Brazil

${ }^{5}$ DDS, MSc, PhD, Professor, Department of Oral Pathology, Institute of Science and Technology, São Paulo State University, São José dos Campos, SP, Brazil

${ }^{6}$ DDS, MSc, PhD, Professor, Department of Restorative Dentistry, Endodontic Division, Institute of Science and Technology, São Paulo State University, São José dos Campos, SP, Brazil

Correspondence:

Bellagio Residence, Edifício San Lorenzo

Ap. 106, Fátima Maria Chagas st., 480

Jabutiana, Aracaju/SE. ZIPCODE: 49095793

felipe_smatos@hotmail.com

\begin{abstract}
Matos FS, Godolphim FJ, Albuquerque-Júnior RLC, Paranhos LR, Rode SM, Carvalho CAT, Ribeiro MAG. Laser phototherapy induces angiogenesis in the periodontal tissue after delayed tooth replantation in rats. J Clin Exp Dent. 2018;10(4):e335-40.

http://www.medicinaoral.com/odo/volumenes/v10i4/jcedv10i4p335.pdf
\end{abstract}

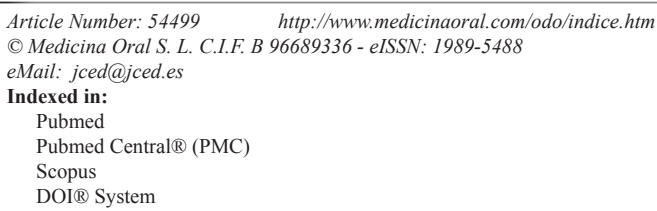

\begin{abstract}
Background: Laser phototherapy (LPT) has been suggested as a new therapeutic tool to improve the repair of replanted teeth. However, its effects and mechanism of action are not yet completely understood.

Objectives: This study evaluated histologically the effect of laser phototherapy (LPT) $\lambda 808$ and $\lambda 660 \mathrm{~nm}$ on angiogenesis in the periodontal tissue of replanted teeth in rats.

Material and Methods: Twenty maxillary right incisors were extracted from twenty Wistar rats and randomly assigned to four groups $(\mathrm{n}=5)$ : $\mathrm{PN}$ - teeth were stored in paper napkin for $45 \mathrm{~min}$; $\mathrm{WM}$ - teeth were immersed in $20 \mathrm{ml}$ of UHT whole cow milk for $45 \mathrm{~min}$; PNL and WML - teeth received the same treatment described for PN and WM, respectively, plus LPT at $\lambda 808$ and $\lambda 660 \mathrm{~nm}$. All root canals were prepared and filled with calcium hydroxide paste. The animals were euthanized 15 days after tooth replantation and angiogenesis was scored by blood vessel counting in the area of periodontal ligament and alveolar bone, using the ImageJ software. Data were analyzed statistically by ANOVA and Tukey's test ( $\alpha=5 \%)$.

Results: LPT at $\lambda 808$ and $\lambda 660 \mathrm{~nm}$ caused significant increased angiogenesis on irradiated groups (PNL and WML) when compared to the non-irradiated groups (PN and WM) $(p<0.05)$. There was no statistically significant difference between PN and WM as well as between PNL and WML ( $p>0.05)$.

Conclusions: LPT is capable of stimulating angiogenesis in vivo in the periodontal tissue of replanted teeth.
\end{abstract}

Key words: Angiogenesis, lasers, tooth avulsion, tooth replantation, wound healing. 


\section{Introduction}

Traumatic tooth avulsion and its treatment are challenging situations in clinical practice. Since most avulsions occur in children aged between 7 and 12 years, replantation and maintenance of the avulsed tooth in its alveolus is essential until facial growth is complete, when a permanent rehabilitative treatment may be performed (1). The traumatic injury causes disruption of the neurovascular bundle and damages multiple periodontal tissue structures, including gingival epithelium, periodontal ligament (PDL), cementum, and alveolar bone, leading to a local inflammatory response, which severity depends mainly on extra-alveolar time and storage media (2).

The immediate replantation of the avulsed tooth within 5 minutes after trauma is one of the most critical factors related to PDL healing. Delayed tooth replantation decreases the probability of periodontal healing to less than $50 \%$ (3). In this case, the tooth should be stored in a suitable media before replantation in order to maintain cell viability and minimize destructive inflammation (4). According to the American Association of Endodontics, Hank's balanced salt solution (HBSS) is considered the best storage media for avulsed teeth, but it is not easily available at the site of accident. Thus, as delayed replantation is the most common situation in cases of avulsion, there is a continuing search for an ideal storage media with clinical efficacy equivalent to HBSS that is readily available $(4,5)$.

Nevertheless, considering that inflammatory root resorption is the main cause of dental replantation failure even when ideal storage conditions have been used $(6,7)$, treatment strategies that limit the extent of the periradicular inflammation, such as laser phototherapy (LPT), have been considered in recent years (8-12). The potential benefits of LPT on periodontal wound repair after tooth replantation are based on a series of biological effects such as anti-inflammatory and analgesic, which accelerate the healing process and reduce the occurrence of root resorption and ankyloses (9-13).

Angiogenesis, that is, the formation of new blood vessels from pre-existing ones, is one of the mechanisms involved in tissue repair, specifically in the proliferative phase (3-7 postsurgical days) (14). It is responsible for supplying the oxygen and nutrients necessary to sustain cell metabolism at the wound area $(15,16)$. Moreover, the stimulation of blood vessel formation has been associated with accelerated and improved tissue repair in experimental models in vivo (17-19). This is why angiogenesis has been widely used as a parameter for the analysis of LPT action on the tissue repair process $(14,15,20-23)$.

Thus, considering there are few reports on the effects of LPT on periodontal healing after tooth replantation and that its mechanism of action is not yet completely understood, this study aimed to investigate the effect of LPT ( $\lambda 808 \mathrm{~nm}$ and $\lambda 660 \mathrm{~nm})$ on angiogenesis in the periodontal tissue of replanted teeth in rats, after being stored in paper napkin or whole cow milk for $45 \mathrm{~min}$. This analysis will help to elucidate aspects of the repair process in tooth replantation that so far have more often been investigated histomorphometrically (8-12).

\section{Material and Methods}

- Experimental model and sample:

The Animal Research Ethics Committee approved this randomized single-blinded in vivo experimental study (process n. 041114). Twenty male Wistar rats (Rattus norvegicus albinus) weighing 200-250 g were used. The animals were housed in collective cages $(49 \times 34 \times 16 \mathrm{~cm})$ with five animals in each one, under standard conditions of temperature $\left(22 \pm 2^{\circ} \mathrm{C}\right)$, relative humidity $(55 \pm 10 \%)$, and light/dark cycle (12/12 h). They were fed with solid rations of Labina ${ }^{\mathrm{TM}}$ (Purina, São Paulo, SP, Brazil) and water ad libitum, except for the postoperative $12 \mathrm{~h}$ (12). - Tooth extraction:

Before the surgical procedures, the rats were sedated and anesthetized with intraperitoneal injection of a mixture of Ketamine (Syntec do Brazil Ltda., Cotia, SP, Brazil) and Xylazine (Syntec do Brazil Ltda., Cotia, SP, Brazil) in the proportion of $0.75 / 0.5 \mathrm{ml}$ and in a dose of $0.1 \mathrm{ml}$ per $100 \mathrm{~g}$ of body weight. After intraoral antisepsis of the anterior maxillary portion with $0.12 \%$ chlorhexidine gluconate (Colgate-Palmolive Industrial Ltda., São Bernardo do Campo, SP, Brazil), the maxillary right incisor of each rat was extracted using a Buser elevator (Trinity Indústria e Comércio Ltda., São Paulo, SP, Brazil) and an adapted forceps \#150 (Golgran Ind. Com. Instr. Odontológico Ltda., São Caetano do Sul, SP, Brazil), simulating a case of tooth avulsion (12).

- Division of groups:

Teeth were randomly assigned to four groups of 5 specimens each, according to the treatment given: PN group - teeth were stored in paper napkin (Santhe ${ }^{\mathrm{TM}}$ - Fábrica de Papel Santa Therezinha S.A., Bragança Paulista, SP, Brazil); PNL group - teeth received the same treatment described for PN plus LPT at $\lambda 808 \mathrm{~nm}$ and $\lambda 660 \mathrm{~nm}$; WM group - teeth were immersed in $20 \mathrm{ml}$ of UHT whole cow milk (Italac, Santa Helena de Goiás, GO, Brazil); WML group - teeth received the same treatment described for WM plus LPT at $\lambda 808 \mathrm{~nm}$ and $\lambda 660 \mathrm{~nm}$. All teeth were maintained in their respective storage media for 45 minutes at room temperature $\left(22 \pm 2^{\circ} \mathrm{C}\right)(12)$.

- Root canal treatment:

After this period, the dental papilla of each extracted tooth was excised with a \#15 scalpel blade (Suzhou Kyuan Medical Apparatus Co. Ltda., Beiqiao Town, Suzhou City, China) to expose the root canal, and the pulp was extirpated via the apical foramen with a slightly pre-curved \#20 Hedstrom file (Dentsply Maillefer, Ballaigues, Switzerland) in order to control the continuing growth 
of the rat incisor and prevent necrosis of the pulp tissue subsequent to the extraction. The root canals were gently irrigated with $5 \mathrm{ml}$ of saline solution (Farmax, Divinópolis, MG, Brazil), dried with absorbent paper points (Dentsply Ind. e Com. Ltda., Petrópolis, RJ, Brazil), and filled with calcium hydroxide paste (UltraCal ${ }^{\mathrm{TM}}$ XS, Ultradent Products Inc., South Jordan, UT, USA) using $25 \times 0.35-\mathrm{mm}$ capillary tips (Ultradent Products Inc., South Jordan, UT, USA) (12).

- Tooth replantation:

Before replantation, antisepsis of the anterior maxilla with $0.12 \%$ chlorhexidine gluconate was again performed, and an alveolar lavage was done with $2 \mathrm{ml}$ of saline solution for clot removal. The PNL and WML groups were treated with LPT at $\lambda 808 \mathrm{~nm}$ and $\lambda 660 \mathrm{~nm}$ according to the protocol described subsequently. Teeth were replanted into their sockets with a slow and delicate movement using clinical tweezers (Golgran Ind. Com. Instr. Odontológico Ltda., São Caetano do Sul, SP, Brazil). Soon after, the animals received a single intramuscular injection of an antibiotic (Megacilin Super Plus ${ }^{\mathrm{TM}}$, Vansil Ind. Com. e Repr. Ltda., Descalvado, SP, Brazil) diluted in $15 \mathrm{ml}$ of sterile water (Samtec Biotecnologia, Ribeirão Preto, SP, Brazil), in a dose of $0.005 \mathrm{ml}$ per 100 $\mathrm{g}$ of body weight (12).

- LPT protocol:

In the PNL and WML groups prior to replantation, the mesial and distal root surface of each tooth and the inside of the alveolus were irradiated with a gallium-aluminum-arsenate (GaAlAs) continuous-wave $(\mathrm{CW})$ diode laser (Photon Lase IIITM, DMC Equipamentos Ltda., São Carlos, SP, Brazil), emitted at $\lambda 808 \mathrm{~nm}$ wavelength (infrared light), $100 \mathrm{~mW}$ output power, $3.6 \mathrm{~W} / \mathrm{cm}^{2}$ power density, $1.7 \mathrm{~J}$ total energy per point, and $61 \mathrm{~J} / \mathrm{cm}^{2}$ energy density. The laser was applied in a punctual mode in contact with the root surface and the alveolus entry, with a total irradiation time of $119 \mathrm{~s}$, as follows: $17 \mathrm{~s}$ for each cervical, middle, and apical thirds of the proximal root faces (mesial/distal) and $17 \mathrm{~s}$ for the inside of the alveolus (12).

After replantation, another laser irradiation was carried out on the buccal and palatal mucosa of the alveolus containing the replanted tooth with an indium-gallium-aluminum-phosphorus (InGaAlP) CW diode laser (Photon Lase IIITM, DMC Equipamentos LTDA, São Carlos, SP, Brazil), emitted at $\lambda 660 \mathrm{~nm}$ wavelength (visible light) with the same parameters described for the $\lambda 808 \mathrm{~nm} \mathrm{Ga}-$ AlAs laser, except the total exposure time was $34 \mathrm{~s} \mathrm{(17}$ $\mathrm{s}$ for each buccal and palatal mucosa). This procedure was repeated every 48 hours until completing five sessions of LPT at $\lambda 660 \mathrm{~nm}$. The Photon Lase IIITM device used in this investigation has the following characteristics: $1.9-\mathrm{mm}$ laser beam diameter on the handpiece tip, $0.028-\mathrm{cm} 2$ beam area, 17-degree beam divergence, and 50-degree tip angle (12).
- Euthanasia and histological processing:

The rats were euthanized by the inhalatory chemical method in carbon dioxide gas chamber, 15 days after replantation. The anatomic pieces containing the replanted teeth were removed, fixed in $10 \%$ formaldehyde for 7 days, and decalcified in 5\% nitric acid for 14 days, with solution exchanges every 48 hours. After that, the pieces were dehydrated, clarified, embedded in paraffin, and sectioned (5- $\mu \mathrm{m}$ thick) in a longitudinal plane of the root (12). Three microscope slides per piece, each containing one histological section, were prepared and stained with hematoxylin and eosin (HE) for histological analysis.

- Histological analysis:

Images were captured with a digital camera (Olympus Camedia C-7070; Olympus Corporation, Tokyo, Japan) attached to a microscope (Olympus CX31; Olympus Corporation, Tokyo, Japan) at 100x magnification. Histological analysis was performed only in the middle third of the palatal root face because this region is not damaged by the surgical procedures (24), and because the rat tooth has cementum and periodontal ligament only on this face and on parts of the mesial and distal faces of the root (25). Angiogenesis was measured in the area of periodontal ligament and alveolar bone by counting the number of blood vessels in two fields per histological section using ImageJ software (Wayne Rasband, National Institutes of Health, USA), without distinguishing their nature (arterioles, venules, and capillaries), as shown in Figure 1. The examiner was blinded to which groups the images belonged in order to avoid bias during the analysis.

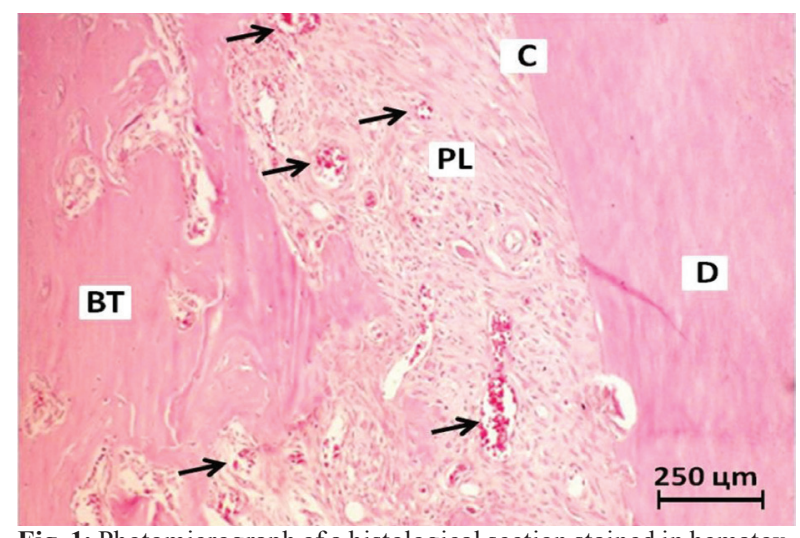

Fig. 1: Photomicrograph of a histological section stained in hematoxylin-eosin showing an intense presence of blood vessels (arrows) on periodontal wound. Dentin (D), cementum (C), periodontal ligament (PL), bone tissue (BT). Original magnification $100 \times$.

- Statistical analysis:

The mean of blood vessels per specimen was obtained, which generated the mean per group, and consequently the standard error of the mean. These values were obtained and analyzed statistically with ANOVA and Tukey's 
test after data from all groups had normality accepted by the Shapiro-Wilk test. The BioEstat 5.0 statistical software was used and the significance level was set at $5 \%$ $(p<0.05)$.

\section{Results}

The Figure 2 shows the mean of blood vessels and standard error of the mean (SEM) per group. When comparing irradiated (PNL and WML) and non-irradiated (PN and WM) groups, statistical analysis showed a significant increase of angiogenesis in irradiated groups $(p<0.05)$ (Fig. 2). Regarding the storage media for avulsed teeth used during the extra-alveolar time, there was no statistically significant difference between PN and WM $(p>0.05)$ as well as between PNL and WML $(p>0.05)$ (Fig. 2).

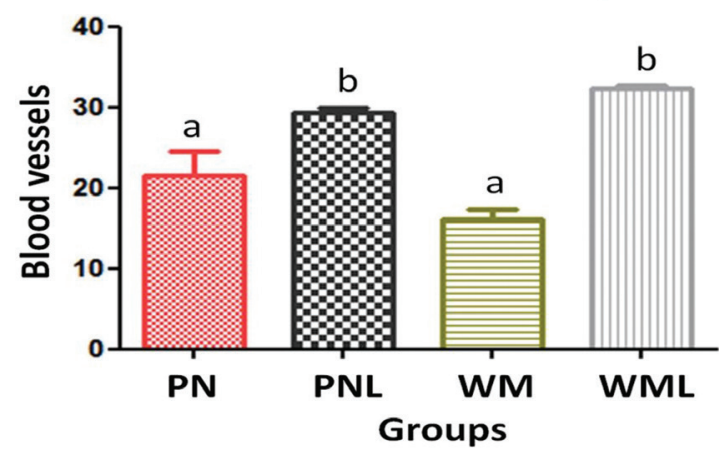

Fig. 2: Mean \pm SEM of blood vessels per group and statistical differences among the groups. Statistical analysis by ANOVA followed by Tukey's test. Bars with different letters differ significantly among each other $(p<0.05)$.

\section{Discussion}

Several studies have been developed for decades to investigate the effects of red and/or infrared laser lights on tissue repair $(8-12,14,15,20,21,23,26)$ but only few recent works have studied their effects on the periodontal repair process of replanted teeth (8-12). Although some reports have shown that LPT is capable of improving the periodontal repair process of replanted teeth in vivo by reducing the occurrence of inflammatory root resorption and ankyloses (9-12), its effects are still inconclusive because of the lack of studies, the methodological differences mainly in LPT protocols, and the many variables that may alter the response of biological tissues (12).

The present study used a combination of infrared $(\lambda 808$ $\mathrm{nm})$ and red laser $(\lambda 660 \mathrm{~nm})$, because some studies have suggested that this association is more effective in reducing the inflammatory process and accelerating tissue repair, as different wavelengths would have different absorption and penetration (12,27-29). Irradiation of the root surface with infrared laser was based on findings of Carvalho et al. (9) and irradiation of the alveolar walls and vestibular/palatine mucosa with red laser was based on findings of Vilela et al. (10), who showed less root resorption areas in laser groups using their respective wavelengths. In order to determine whether the effect of LPT on periodontal healing after tooth replantation was positive, the specimens were microscopically assessed by means of quantitative analysis of blood vessels in the periodontal tissue, also known as angiogenesis, a key process for wound healing $(14-23,30)$.

According to our results, 15 days after tooth replantation, LPT at $\lambda 808 \mathrm{~nm}$ and $\lambda 660 \mathrm{~nm}$ significantly increased angiogenesis in the periodontal tissue on irradiated groups (PNL and WML), indicating a positive effect of these wavelengths on periodontal healing of replanted teeth. These findings agree with previous studies that have indicated that the use of both infrared and red lasers are capable of stimulating angiogenesis in vivo on skin and oral wounds, resulting in a major increase of both oxygen supply and nutrients to the wound $(14,20,23)$. Medeiros et al. (21) and Wagner et al. (15) similarly reported this phenomenon on skin and oral wound healing in rats, respectively, irradiated with red laser $(\lambda 660 \mathrm{~nm})$. The mechanism of action of LPT on angiogenesis and tissue repair can be explained through the stimulation of photosensitive chromophores such as cytochrome $\mathrm{C}$ oxidase, an enzyme found in the internal membrane of the mitochondria. When stimulated, these enzymes accelerate cellular metabolism throughout the increment of adenosine triphosphate (ATP) synthesis, providing energy for cellular activities that are essential for the processes of mitosis and protein synthesis (29). These events favor the healing process through increased cell proliferation, production of nucleic acids, formation of collagen, and reduction of inflammation $(12,14,15,20$ 23,26).

Possibly, angiogenesis is also induced by laser phototherapy through different cellular signaling mechanisms. Cury et al. (14) showed that both infrared and red lasers increased the expression of vascular endothelial growth factor (VEGF), hypoxia inducible factor (HIF-1 $\alpha$ ), and modulated matrix metalloproteinase (MMP-2) activity, which are three major mediators involved in angiogenesis. The VEGF plays a key role in angiogenesis by stimulating the proliferation and migration of endothelial cells and HIF- $1 \alpha$ regulates the cellular response to hypoxia by activating genes that are important to cellular adaptation under hypoxic conditions. The activity of MMP-2 is necessary for vascular basement membrane degradation and extracellular matrix remodeling, in order to allow the migration of endothelial cells during angiogenesis (14).

Cytokine modulation is another basic mechanism whereby LPT increases angiogenesis and improves tissue repair (16). Recent experimental research has showed that LPT at $\lambda 660 \mathrm{~nm}$ increased the tissue levels of IL-1 $\beta$ at the early stage of oral wound healing and decreased the 
tissue levels of TNF- $\alpha$ during all stages of oral wound healing (15). Among its several roles during wound healing, IL-1 $\beta$ is capable of acting directly and indirectly on endothelial cells by activating infiltrating cells to produce endothelial cell-activating factors such as VEGF. Thus, the increase in IL-1 $\beta$ tissue levels induced by LPT at the early (inflammatory) phase of wound healing could be associated with its pro-angiogenic effect. The TNF- $\alpha$ is a pro-inflammatory cytokine that, in excess, is associated with chronic and slow-healing acute wounds $(15,30)$.

A greater proliferation of blood vessels was expected when whole cow milk was used as storage media, because it presents better conditions for the periodontal repair process by providing some nutrients and growth factors $(12,31,32)$. Paper napkin, on the other hand, does not provide any benefit to maintaining the vitality of PDL cells, besides presenting higher risk of bacterial contamination (12). However, the results of this research revealed that the effects of storage solutions on angiogenesis were similar for both whole cow milk and paper napkin, which can be justified by the triggering of a local adaptive response through a physiological mechanism of compensation to the nutritional deficiency caused by the dry environment.

In a previous study (12), our team showed, through histomorphometric analysis, that whole cow milk, as well as soy milk, provided better conditions for the periodontal repair process, reducing the occurrence of root resorption and ankylosis. This finding suggests that the storage media can improve the repair process by other biological mechanisms involved in periodontal repair, such as favoring the regeneration of the PDL by providing essential metabolites for cell maintenance (12,33-35), and not stimulating angiogenesis. Regarding the effects of LPT, the findings of the present investigation are in agreement with previous studies that observed a significant improvement in the process of periodontal repair in the irradiated groups (9-12), confirming the assumption that the stimulation of blood vessel formation is associated with accelerated and better tissue repair (17-19).

We may conclude that LPT at $\lambda 808 \mathrm{~nm}$ and $\lambda 660 \mathrm{~nm}$ improved the periodontal repair 15 days after tooth replantation as evidenced by the increased blood vessel formation or angiogenesis, regardless of the storage media. Thus, LPT could be used as a new therapeutic strategy to accelerate and improve the periodontal repair process of replanted teeth. Nevertheless, further studies should be performed to clarify red and infrared laser effects on periodontal healing and to confirm its correlation with angiogenesis.

\section{References}

1. Trope M. Avulsion of permanent teeth: theory to practice. Dent Traumatol. 2011;27:281-294.
2. Andreasen JO. Challenges in clinical dental traumatology. Dent Traumatol. 1985;1:45-55.

3. Andreasen JO, Borum MK, Jacobsen HL, Andreasen FM. Replantation of 400 avulsed permanent incisors. 4. Factors related to periodontal ligament healing. Endod Dent Traumatol. 1995;11:76-89.

4. Andersson L, Andreasen JO, Day P, Heithersay G, Trope M, DiAngelis AJ, et al. International Association of Dental Traumatology guidelines for the management of traumatic dental injuries: 2. Avulsion of permanent teeth. Dent Traumatol. 2012;28:88-96.

5. Hiremath G, Kidiyoor KH. Avulsion and storage media. J Investig Clin Dent. 2011;2:89-94.

6. Andreasen JO. Effect of extra-alveolar period and storage media upon periodontal and pulpal healing after replantation of mature permanent incisors in monkeys. Int J Oral Surg. 1981;10:43-53.

7. Tronstad L. Root resorption - etiology, terminology and clinical manifestations. Endod Dent Traumatol. 1988;4:241-252.

8. Saito CTMH, Gulinelli JL, Panzarini SR, Garcia VG, Okamoto R, Okamoto T, et al. Effect of low-level laser therapy on the healing process after tooth replantation: a histomorphometrical and immunohistochemical analysis. Dent Traumatol. 2011;27:30-39.

9. Carvalho EDS, Costa FTS, Campos MS, Anbinder AL, Neves ACC, Habitante SM, et al. Root surface treatment using diode laser in delayed tooth replantation: radiographic and histomorphometric analyses in rats. Dent Traumatol. 2012;28:429-436.

10. Vilela RG, Gjerde K, Frigo L, Leal ECP, Lopes-Martins RAB, Kleine BM, et al. Histomorphometric analysis of inflammatory response and necrosis in re-implanted central incisor of rats treated with low-level laser therapy. Lasers Med Sci. 2012;27:551-557.

11. Carvalho FB, Andrade AS, Barbosa AFS, Aguiar MC, Cangussu MCT, Pinheiro ALB, et al. Evaluation of laser phototherapy $(780 \mathrm{~nm})$ after dental replantation in rats. Dent Traumatol. 2016;32:488-494.

12. Matos FS, Godolphim FJ, Correia AMO, Albuquerque Júnior RLC, Paranhos LR, Rode SM, et al. Effect of laser photobiomodulation on the periodontal repair process of replanted teeth. Dent Traumatol. 2016;32:402-408.

13. Parker S. Low-level laser use in dentistry. Br Dent J. 2007;202:131138.

14. Cury V, Moretti AIS, Assis L, Bossini P, Crusca JS, Neto CB, et al. Low level laser therapy increases angiogenesis in a model of ischemic skin flap in rats mediated by VEGF, HIF-1 $\alpha$ and MMP-2. J Photochem Photobiol B Biol. 2013;125:164-170.

15. Wagner VP, Curra M, Webber LP, Nör C, Matte U, Meurer L, et al. Photobiomodulation regulates cytokine release and new blood vessel formation during oral wound healing in rats. Lasers Med Sci. 2016;31:665-671.

16. Tonnesen MG, Feng X, Clark RA. Angiogenesis in wound healing. J Investig Dermatol Symp Proc. 2000;5:40-46.

17. Kong P, Xie X, Li F, Liu Y, Lu Y. Placenta mesenchymal stem cell accelerates wound healing by enhancing angiogenesis in diabetic Goto-Kakizaki (GK) rats. Biochem Biophys Res Commun. 2013;438:410-419.

18. McLaughlin PJ, Immonen JA, Zagon IS. Topical naltrexone accelerates full-thickness wound closure in type 1 diabetic rats by stimulating angiogenesis. Exp Biol Med. 2013;238:733-743.

19. Navone SE, Pascucci L, Dossena M, Ferri A, Invernici G, Acerbi F, et al. Decellularized silk fibroin scaffold primed with adipose mesenchymal stromal cells improves wound healing in diabetic mice. Stem Cell Res Ther. 2014;5:7.

20. Sousa APC, Paraguassú GM, Silveira NTT, Souza J, Cangussú MCT, Santos JN, et al.. Laser and LED phototherapies on angiogenesis. Lasers Med Sci. 2013;28:981-987.

21. Medeiros ML, Araújo-Filho I, Silva EMN, Queiroz WSS, Soares $\mathrm{CD}$, Carvalho MGF, et al. Effect of low-level laser therapy on angiogenesis and matrix metalloproteinase-2 immunoexpression in wound repair. Lasers Med Sci. 2016;32:35-43.

22. Góralczyk K, Szymanska J, Lukowicz M, Drela E, Kotzbach R, Dubiel M, et al. Effect of LLLT on endothelial cells culture. Lasers Med Sci. 2015;30:273-278.

23. Fahimipour F, Houshmand B, Alemi P, Asnaashari M, Tafti MA, 
Akhoundikharanagh F, et al. The effect of He-Ne and Ga-Al-As lasers on the healing of oral mucosa in diabetic mice. J Photochem Photobiol B Biol. 2016;159:149-154.

24. dos Santos CLV, Sonoda CK, Poi WR, Panzarini SR, Sundefeld MLMM, Negri MR. Delayed replantation of rat teeth after use of reconstituted powdered milk as a storage medium. Dent Traumatol. 2009;25:51-57.

25. Eccles JD. The development of the periodontal membrane in the rat incisor. Arch Oral Biol. 1964;9:127-133.

26. Matos FS, Soares AF, Albuquerque Júnior RLC, Ribeiro SO, Lima GDN, Novais SMA, et al. Effect of laser therapy on the inflammatory response induced by endodontic medications implanted into the subcutaneous tissue of rats. Rev Odontol da UNESP. 2014;43:343-350.

27. Santos NRS, Sobrinho JBM, Almeida PF, Ribeiro AA, Cangussú MCT, Santos JN, et al. Influence of the combination of infrared and red laser light on the healing of cutaneous wounds infected by Staphylococcus aureus. Photomed Laser Surg. 2011;29:177-182.

28. Marinho RR, Matos RM, Santos JS, Ribeiro MAG, Smaniotto S, Barreto EO, et al. Potentiated anti-inflammatory effect of combined $780 \mathrm{~nm}$ and $660 \mathrm{~nm}$ low level laser therapy on the experimental laryngitis. J Photochem Photobiol B. 2013;121:86-93.

29. Lima FJC, Oliveira Neto OB, Barbosa FT, Galvão AMN, Ramos FWS, Lima CCF, et al. Is there a protocol in experimental skin wounds in rats using low-level diode laser therapy (LLDLT) combining or not red and infrared wavelengths? Systematic review. Lasers Med Sci. 2016;31:779-787.

30. Behm B, Babilas P, Landthaler M, Schreml S. Cytokines, chemokines and growth factors in wound healing. J Eur Acad Dermatology Venereol. 2011;26:812-820.

31. Ashkenazi M, Sarnat H, Keila S. In vitro viability, mitogenicity and clonogenic capacity of periodontal ligament cells after storage in six different media. Endod Dent Traumatol. 1999;15:149-156.

32. Pearson RM, Liewehr FR, West LA, Patton WR, McPherson JC, Runner RR. Human periodontal ligament cell viability in milk and milk substitutes. J Endod. 2003;29:184-186.

33. Udoye CI, Jafarzadeh H, Abbott PV. Transport media for avulsed teeth: a review. Aust Endod J. 2012;38:129-136.

34. Malhotra N. Current developments in interim transport (storage) media in dentistry: an update. Br Dent J. 2011;211:29-33.

35. Moura CCG, Soares PBF, Reis MVDP, Fernandes Neto AJ, Soares CJ. Soy milk as a storage medium to preserve human fibroblast cell viability: an in vitro study. Braz Dent J. 2012;23:559-563.

Acknowledgments

The authors would like to thank FAPITEC/SE (Foundation for Research and Technological Innovation Support of the State of Sergipe) and CAPES (Coordination for the Improvement of Higher Education Personnel) for funding the execution of this work through PROMOB.

\section{Conflict of interest}

The authors declare that they have no conflict of interest in this study. 